\title{
Editorial
}

Joachim W. Dudenhausen* and Heike Jahnke

\section{The journal Case Reports in Perinatal Medicine starts with Open Access}

https://doi.org/10.1515/jpm-2021-0609

Ten years ago the Editors and Publisher of the Journal of Perinatal Medicine, De Gruyter, were inspired to start a new journal entitled Case Reports in Perinatal Medicine (CRPM) with the aim to collect cases with uncommon diagnosis, and to describe new diseases, innovative therapeutic methods and unusual side effects in therapy. The journal publishes case reports and results of small group studies. These reports generate research questions and induce prospective studies. For this reason, these case reports and CRPM have a high educational value in the world of evidence-based medicine.

After several years of online only publication, the publisher De Gruyter and the journal's management have decided to switch from subscription to open access publication starting in 2022. This is a significant change in the journal's profile and an important milestone in the development of CRPM.

The journal's scientific aims will not change as a result of the decision to change to open access. CRPM will continue to publish competent and timely case reports covering clinical, methodological and scientific aspects of perinatology. All manuscripts will continue to be critically reviewed by at least two experts in the field.

In contrast to many newly founded open access journals, CRPM looks back on 10 years of sound and evidencebased publication results, and has been accepted as a serious journal published by an internationally well accepted publishing house.

Until now, the costs of publishing CRPM have been covered by subscription fees. With the change to open access in 2022, CRPM will introduce article processing charges (APCs) to cover processing and publication costs. Authors will be charged a reduced fee of $350 €$, which is only due after the article has been accepted.

The decision to continue CRPM as an open access journal was made in light of the changing publication landscape, which poses new challenges and necessitates a shift to new publication models.

*Corresponding author: Professor Joachim W. Dudenhausen, MD, FRCOG(ae) FIAPM, Editor-in-Chief, Journal of Perinatal Medicine, Berlin, Germany, E-mail: joachim.dudenhausen@charite.de Heike Jahnke, De Gruyter Publisher, Berlin, Germany 